\title{
Hospitals turning to team-based conflict resolution
}

W

hen it comes to conflicts in the workplace, counsellors who specialize in physician well-being are increasingly working with entire teams rather than with only the individuals involved.

In both the individual and team approaches, physicians who are bullying or disruptive are provided oneon-one therapy. However, in the "workplace approach," all staff participate in meetings and workshops that improve communication skills and encourage employees to voice their concerns, listen to others' concerns and rebuild trust.

"While individual treatment works for things like substance-use disorders, it's not usually enough for interpersonal conflict," says Claire Sauvé, education coordinator for the Physician Health Program of British Columbia, which has taken a workplace approach to conflict resolution for the past three years. "It can be difficult for other staff to trust that things will be better when the physician re-enters the workplace."

Sauvé says the physician workplace environment is especially prone to interpersonal conflict because the medical field tends to value precision and control over emotional needs such as compassion and understanding.

"Physicians are used to diagnosing and making quick decisions," says Sauvé, who explains that if physicians carry that habit into interpersonal communication, it often leads them to make assumptions without giving others the chance to explain themselves. "People want to know they have been acknowledged and understood."

Last year, the Alberta Medical Association launched its Healthy Workplace Initiative, and the Ontario Medical Association (OMA) introduced its Physician Workplace Support Program. The programs employ slightly different models and methods but both are based on "systems theory," which suggests that "behaviour occurs in a workplace context," says Mary

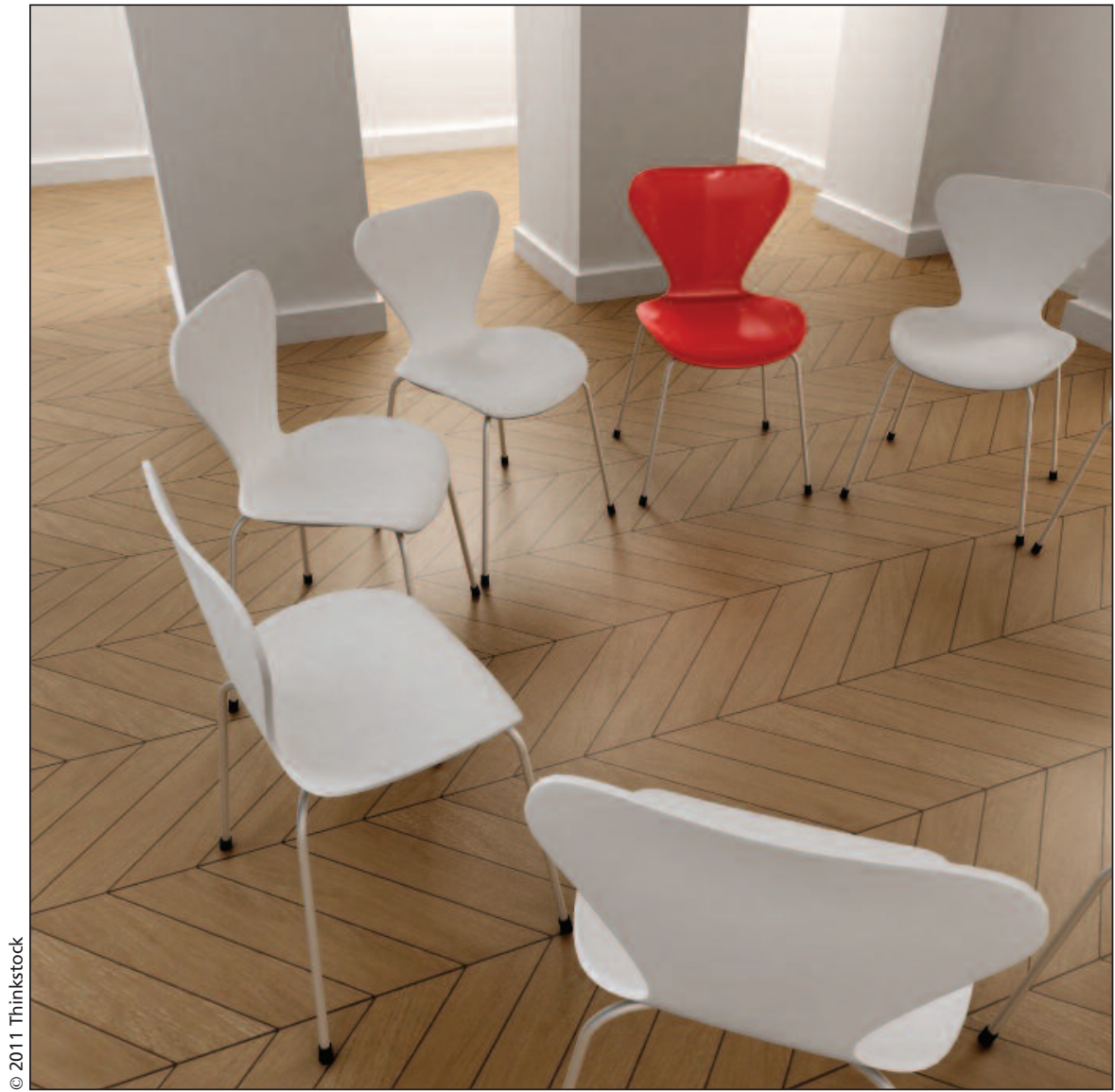

In the "workplace approach" to resolving conflict between hospital employees, all staff meet in one room and work to improve communication skills and rebuild trust.

Yates, director of the OMA's program. In other words, how staff respond to a physician, the physician's level of responsibility and numerous other factors influence that particular physician's behaviour, according to Yates.

There are no published studies yet on the success rate of the Ontario, $\mathrm{BC}$ or Alberta programs, but a United States study of 38 groups at veteran health centres found that those who underwent facilitated team meetings reported higher respect, cooperation and understanding of differences in the workplace than members of control groups ( $\mathrm{J} \mathrm{Appl}$ Behav Sci 2009;45:384-410).

The programs are in demand and are especially called upon when staff members threaten lawsuits or refuse to work with a colleague, says Sauvé. In the past year, the OMA's program has been used in 20 physician workplaces to help to resolve conflicts, according to Yates.

"Our strategies are all very customized to the individual workplace," says Yates. "In one case, one of the reasons the doctor was in trouble is that he never received feedback from anybody, so we talked with staff about how to give feedback in a way that is respectful."

Sauvé's team, meanwhile, facilitates routine staff meetings to identify patterns of poor communication and train staff in "compassionate communication" methods.

The programs are not always an easy sell, admits Yates. "Do physicians feel singled out? Yes," she says.

Sauvé adds that some staff have at 
times refused to participate on the grounds that the issue is with the physician, not them.

However, staff become engaged in the program when they see that issues of stress, heavy workload and communication problems are being addressed in a systemic way, Yates says.

Michael Leiter, an organizational psychologist who helps health teams work more productively and effectively together through his program, Civility, Respect and Engagement in the Workplace, says a workplace approach is necessary in interpersonal conflict.

"There are individuals who have very serious problems relating to each other," says Leiter. "But people also react in a way that elicits problematic behaviour, and workplaces have a tendency to get their scapegoats and individualize it."

At the same time, says Leiter, work- place approaches need to be carefully executed. "If you go in and do one session and you open cans of worms, it would just be very disruptive," he says, adding that weekly meetings over a period of six months are often necessary to create sustained improvements in workplace interactions. - Wendy Glauser, Toronto, Ont.

CMAJ 2011. DOI:10.1503/cmaj.109-3961 